\title{
Effect of ausaging on the morphology of martensite in an $\mathrm{Fe}-25 \% \mathrm{Ni}-7.5 \% \mathrm{Si}$ alloy
}

\author{
Y. Himuro, O. Ikeda, R. Kainuma and K. Ishida \\ Department of Materials Science, Graduate School of Engineering, Tohoku University, Aramaki \\ Aoba-yama 02, Sendai 980-8579, Japan
}

\begin{abstract}
The martensitic transformations in an Fe-25\%Ni-7.5\%Si (mass\%) alloy ausaged under various conditions were investigated by means of optical and transmission electron microscopy, differential scanning calorimetry, electrical resistivity-temperature measurements and hardness-testing. It was clarified that nanoscale particles of $\gamma^{\prime}-(\mathrm{Ni}, \mathrm{Fe})_{3} \mathrm{Si}$ with $\mathrm{Ll}_{2}$ structure were formed in the austenite matrix by ausaging between 400 and $600^{\circ} \mathrm{C}$, while no precipitation occurred due to ausaging at $700^{\circ} \mathrm{C}$. The Ms temperature was depressed by ausaging at 400 and $500^{\circ} \mathrm{C}$, but hardly changed when the ausaging temperature was $600^{\circ} \mathrm{C}$. It was observed that the morphology of martensite which was lenticular in unaged specimen changed to a mixture of lenticular and thin plate by ausaging at below $600^{\circ} \mathrm{C}$.
\end{abstract}

\section{INTRODUCTION}

It has been established that the morphologies of the $\alpha^{\prime}$ martensite phase formed from the $\gamma$ phase in the iron alloys are classified into five types of lath, butterfly, $(225)_{\mathrm{A}}$ type plate, lenticular and thin-plate. These morphologies have been discussed in terms of the Ms temperature, the stacking fault energy of austenite, the crystal structure of martensite, the relative strengths of martensite and austenite, etc., as reviewed by Maki [1]. Among these $\alpha$ ' martensites, only the thin-plate martensite, which has been observed in several alloys such as $\mathrm{Fe}-\mathrm{Ni}-\mathrm{C}[2,3]$, Fe-Pt [4, 5], Fe-Ni-Co-Ti [6], etc., has the potential of showing the perfect shape memory effect. It is well known that the long-range ordering of austenite to the $\mathrm{Ll}_{2}$ structure or the coherent precipitates of $\gamma^{\prime}-(\mathrm{Ni}, \mathrm{Fe}, \mathrm{Co})_{3} \mathrm{Ti}$ with the $\mathrm{LI}_{2}$ structure induces the formation of thin-plate martensite in the case of Fe-Pt [5] or Fe-Ni-Co-Ti [6] alloy, respectively.

Phase equilibria of the Fe-rich portion [7] and martensitic transformation of the $\gamma$ phase [8] in Fe-Ni-Si alloy have been studied by the present authors. Figure 1 shows the phase equilibria and Ms temperature of unaged specimens of $\mathrm{Fe}-25 \% \mathrm{Ni}-\mathrm{Si}$ alloy. It is seen that the atomic ordering of $\alpha(\mathrm{A} 2) \rightarrow$ $\alpha_{1}(\mathrm{~B} 2)$ and $\alpha_{1} \rightarrow \alpha_{2}\left(\mathrm{D0}_{3}\right)$ transitions occurs in the $\mathrm{BCC}$ phase region with high Si content and that there is very strong attractive interaction between the Fe or $\mathrm{Ni}$ and $\mathrm{Si}$ atoms. The $\mathrm{Ms}$ temperature is depressed with increasing Si content and martensite morphology changes from lath to lenticular. We have also found that the thin-plate martensite is formed in the $\mathrm{Fe}-27 \% \mathrm{Ni}-8 \% \mathrm{Si}$ and $\mathrm{Fe}-28 \% \mathrm{Ni}-7.5 \% \mathrm{Si}$ alloys of which the Ms temperatures are very low $\left(\mathrm{Ms}<-180^{\circ} \mathrm{C}\right.$ ) [8]. Moreover, the $\gamma$ parent phase of those alloys shows short-range ordering of the $\mathrm{Ll}_{2}$

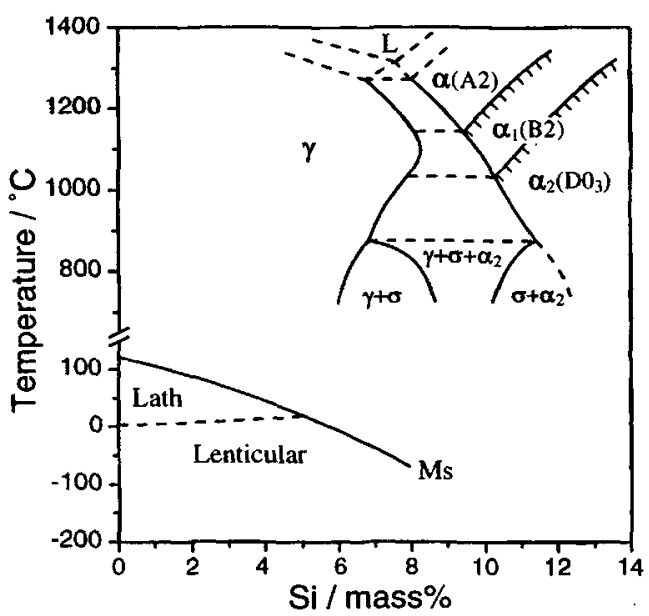

Figure 1: Vertical section diagram in Fe-25\% Ni-Si alloy. Morphology of martensite and $\mathrm{Ms}$ temperature in $\mathrm{Fe}$ $25 \% \mathrm{Ni}-\mathrm{Si}$ alloys quenched from $1100^{\circ} \mathrm{C}$ are also shown. 
structure, which exhibits the partial shape memory effect [9]. All these results indicate that it may be possible to change the martensite morphology from lenticular to thin-plate due to ordering of the austenite which is expected by ausaging. The purpose of this paper is to report the effect of ausaging on the microstructure of austenite and the martensitic transformation in an Fe-25\% Ni-7.5\%Si alloy.

\section{EXPERIMENTAL PROCEDURE}

An $\mathrm{Fe}-25 \% \mathrm{Ni}-7.5 \% \mathrm{Si}$ alloy was prepared from pure $\mathrm{Fe}(99.99 \%), \mathrm{Ni}(99.9 \%)$ and $\mathrm{Si}(99.999 \%)$ by induction melting in an $\mathrm{Al}_{2} \mathrm{O}_{3}$ crucible under an $\mathrm{Ar}$ atmosphere. After being hot-rolled to a sheet of about $3 \mathrm{~mm}$ in thickness, the ingot was austenitized at $1100^{\circ} \mathrm{C}$ for 3 hours in an evacuated quartz tube, and then quenched into ice water. Subsequently, aging treatments were carried out at temperatures in the range from 400 to $700^{\circ} \mathrm{C}$ for various periods up to 10 days. The martensite morphology of the specimens obtained by subzero-cooling into liquid $\mathrm{N}_{2}$ (at $196^{\circ} \mathrm{C}$ ) was examined by optical microscopy. The Ms temperature was determined by differential scanning calorimetry (DSC) with a cooling rate of $10^{\circ} \mathrm{C} / \mathrm{min}$. The hardness of austenite was measured by Vickers micro hardness testing. The microstructure of austenite and martensite was observed by means of transmission electron microscopy (TEM). Thin foil was prepared by electrolytic polishing in a solution of one part perchloric acid and four parts methanol. TEM observations were carried out using a JEM2000EX.

\section{RESURT AND DISCUSSION}

\section{3-1. Precipitation of $\mathrm{L1}_{2}$ particles}

Figures 2 (a) and (b) show the diffraction patterns taken from the austenite phase in specimens ausaged at $700^{\circ} \mathrm{C}$ and $600^{\circ} \mathrm{C}$, respectively. It is seen that the specimen quenched from $700^{\circ} \mathrm{C}$ has the


Figure 2 (a) and (b) : Diffraction patterns taken from the austenite region of the specimen aged at (a) $700^{\circ} \mathrm{C}$ and (b) $600^{\circ} \mathrm{C}$ for 0.5 hours. Incident beam direction is $[011]$.

(c), (d) and (e) : Dark field images taken from the (011) superiattice reflection of (b). The specimens were aged at $600^{\circ} \mathrm{C}$ for (c) 0.5 hours, (d) 4 hours and (e) 13.5 hours. 
disordered FCC (A1) structure, while that quenched from $600^{\circ} \mathrm{C}$ shows superlattice reflections from the $\mathrm{Ll}_{2}$ ordered structure. Dark-field images taken from the $(0 \overline{1} 1)_{\mathrm{L} 12}$ ordered reflection in some alloys aged at $600^{\circ} \mathrm{C}$ for $0.5,4$ and 13.5 hours are shown in Figure 2 (c), (d) and (e), respectively. Nanoscale precipitates with average sizes of about 5, 10 and $15 \mathrm{~nm}$ in diameter were observed in the $0.5,4$ and 13.5 hours specimens, respectively. A similar morphology of the precipitates was also observed in the samples aged at $500^{\circ} \mathrm{C}$ and $400^{\circ} \mathrm{C}$. These results suggest that the $\gamma$ particles with $\mathrm{Ll}_{2}$ structure were coherently precipitated in the austenite matrix by ausaging at below $600^{\circ} \mathrm{C}$.

In order to examine the dissolution of the $\gamma^{\prime}$ precipitates, electric resistance (ER) measurement was carried out. Figure 3 shows the ER curve during heating of the as-quenched specimen. It is seen that there is a singular point at $674^{\circ} \mathrm{C}$, which seems to correspond to the solvus temperature of the $\gamma$ phase in the $\mathrm{Fe}-25 \% \mathrm{Ni}-7.5 \% \mathrm{Si}$ alloy.

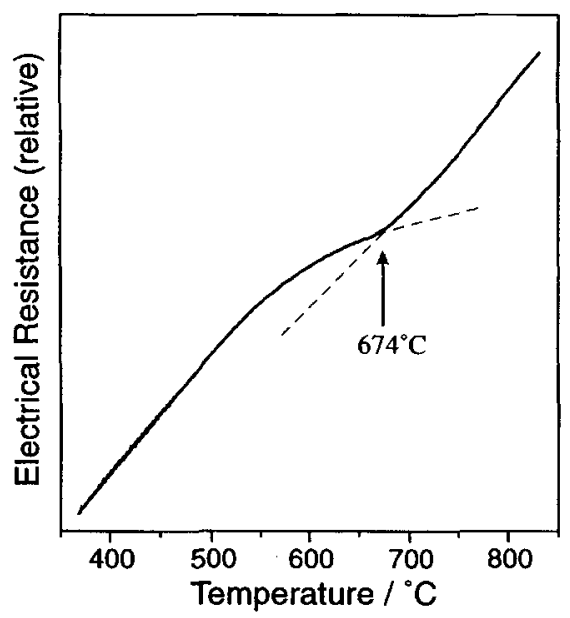

Figure 3 : Resistivity curve of as-quenched specimen during heating. The heating rate was $3^{\circ} \mathrm{C} / \mathrm{min}$.

The $\gamma^{\prime}$ precipitates remarkably influence the hardness of the austenite. Table 1 and Figure 4 show the effect of ausaging time on the Vickers hardness of austenite. It can be seen that the hardness increases by ausaging except for the case at $700^{\circ} \mathrm{C}$ where no $\gamma^{\prime}$ precipitate is observed, as shown in Figure 2 (a). The greatest hardness was obtained for the specimen ausaged at $500^{\circ} \mathrm{C}$. This was caused, however, not only by the precipitation of $\gamma^{\prime}$, but also by the considerable precipitation of the ferrite and $\mathrm{Ni}_{31} \mathrm{Si}_{12}$ phases which were observed in the grain boundary and inner grains.

\section{3-2. Ms temperature}

The Ms temperature depends on ausaging conditions of temperature and time, as shown in Table 1 and Figure 5. The Ms temperature is greatly depressed below $-196^{\circ} \mathrm{C}$ due to ausaging at 400 and $500^{\circ} \mathrm{C}$, while it is hardly changed by aging at $700^{\circ} \mathrm{C}$ at which no $\gamma^{\prime}$ precipitate appears. This result suggests that

\begin{tabular}{|c|c|c|c|c|c|c|c|c|c|}
\hline \multicolumn{2}{|c|}{ Aging Treatment } & \multirow{2}{*}{$\begin{array}{l}\text { Hardness } \\
\text { / HV }\end{array}$} & \multirow{2}{*}{$\mathrm{Ms} /{ }^{\circ} \mathrm{C}$} & \multirow{2}{*}{ Morphology } & \multicolumn{2}{|c|}{ Aging Treatment } & \multirow{2}{*}{$\begin{array}{c}\text { Hardness } \\
\text { / HV }\end{array}$} & \multirow{2}{*}{$\mathrm{Ms} /{ }^{\circ} \mathrm{C}$} & \multirow{2}{*}{ Morphology } \\
\hline Temp $/{ }^{\circ} \mathrm{C}$ & Time / hours & & & & Temp $/{ }^{\circ} \mathrm{C}$ & Time / hours & & & \\
\hline \multirow{2}{*}{\multicolumn{2}{|c|}{ As Solution Treated }} & 136 & -44 & $\mathbf{L}$ & 500 & $1 / 6$ & & -64 & $\overline{\mathbf{L}}$ \\
\hline & & & & & & 0.25 & & -89 & $\mathbf{L}+\mathbf{P}$ \\
\hline \multirow[t]{5}{*}{700} & $1 / 6$ & & -40 & $\mathbf{L}$ & & 0.5 & 164 & -128 & $L+P$ \\
\hline & $2 / 3$ & 136 & -45 & L & & 1 & & $<-196$ & - \\
\hline & 2.25 & 131 & -44 & $\mathrm{~L}$ & & 4 & 187 & $<-196$ & - \\
\hline & 13.5 & 138 & -35 & $\mathrm{~L}$ & & 13.5 & 207 & $<-196$ & - \\
\hline & & & & & & 32 & 228 & $<-196$ & - \\
\hline \multirow[t]{9}{*}{600} & $1 / 6$ & & -49 & L & & 108 & 253 & $<-196$ & - \\
\hline & 0.25 & & -49 & L & & 240 & & $<-196$ & - \\
\hline & 0.5 & 168 & -51 & $\mathbf{L}+\mathbf{P}$ & & & & & \\
\hline & 4 & 197 & -41 & $\mathrm{~L}+\mathrm{P}$ & 400 & 0.5 & 146 & -57 & $\mathbf{L}+\mathbf{P}$ \\
\hline & 13.5 & 206 & -55 & $\mathrm{~L}+\mathrm{P}$ & & 4 & 170 & -100 & $\mathrm{~L}+\mathrm{P}$ \\
\hline & 32 & 207 & -48 & $\mathrm{~L}+\mathrm{P}$ & & 13.5 & 170 & -123 & $\mathrm{~L}+\mathrm{P}$ \\
\hline & 108 & 226 & -48 & $\mathrm{~L}+\mathrm{P}$ & & 32 & 183 & -190 & $\mathrm{~L}+\mathrm{P}$ \\
\hline & & & & & & 108 & 202 & $<-196$ & - \\
\hline & & & & & & 240 & 205 & $<-196$ & - \\
\hline \multicolumn{2}{|c|}{ 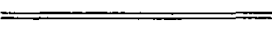 } & & & & & & \multicolumn{3}{|c|}{ L : Lenticular M, P : Thin-Plate $M$} \\
\hline
\end{tabular}


the precipitation of the $\gamma^{\prime}$ phase results in a drastic decrease of Ms. It is well known that such Ms change is related to the additional energy needed for elastic deformation of the coherent $\gamma^{\prime}$-particles which is induced by the martensitic transformation of the matrix phase, as has been discussed in the case of $\mathrm{Fe}-\mathrm{Ni}-\mathrm{Ti}[10]$ and $\mathrm{Fe}-\mathrm{Ni}-\mathrm{Al}$ [11] alloys. It has also been reported that the Ms temperature decreases to a very low temperature below $-196^{\circ} \mathrm{C}$ and then rises again with increasing ausaging time in those alloys. Upon aging of the specimen of $\mathrm{Fe}-25 \% \mathrm{Ni}-7.5 \% \mathrm{Si}$ alloy at 400 and $500^{\circ} \mathrm{C}$, however, the $\mathrm{Ms}$ temperature remained below $-196^{\circ} \mathrm{C}$ even after 10 days. On the other hand, in spite of the precipitation of the $\gamma^{\prime}$ particles, the Ms temperature of the specimen aged at $600^{\circ} \mathrm{C}$ was hardly changed, even in the early stage of aging.

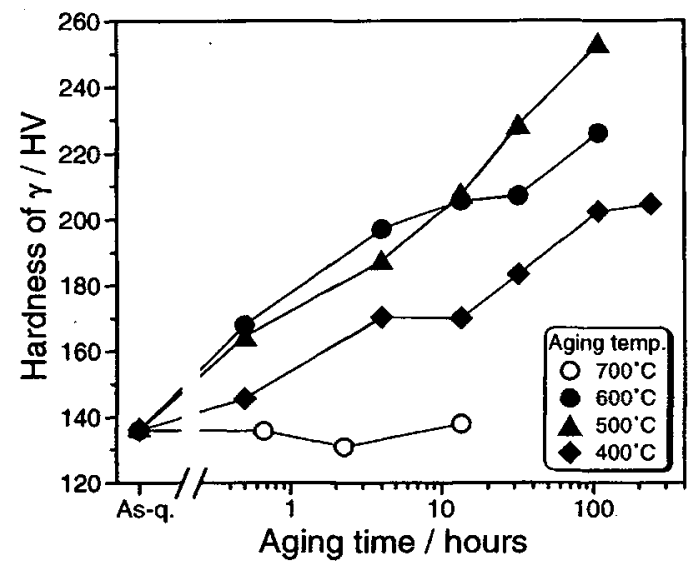

Figure 4 : Changes in hardness of austenite with ausaging time at several temperature.

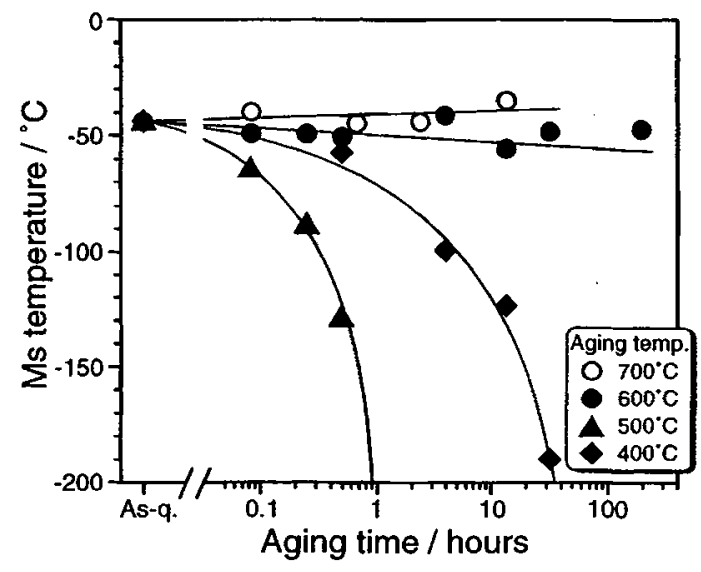

Figure 5 : Changes in Ms temperature with ausaging time at several temperature.

\section{3-3. Morphology of martensite}

The martensite morphology of this alloy, which is lenticular in the as-quenched state, changed due to ausaging except for the specimens aged at $700^{\circ} \mathrm{C}$, and the mixed structure of lenticular and thin-plate martensite was observed in the specimens aged at $400^{\circ} \mathrm{C}$ and $500^{\circ} \mathrm{C}$, as shown in Table 1 and Figure 6. In both cases, it could be seen that the ratio of the volume fraction of thin-plate martensite plates to that of lenticular one increases with ausaging time. It is well known that the Ms temperature is one of the factors determining the morphology of martensite. As shown in Figure 6 (c), the formation of the thin-plate martensite in the specimen ausaged at $400^{\circ} \mathrm{C}$ for 32 hours may be explained by the fact that the Ms temperature of this specimen was $-190^{\circ} \mathrm{C}$.

It is interesting to note that even though the Ms temperature was nearly equal to that of the unaged specimen, not only lenticular but also the thin-plate martensite was observed in the specimens aged at $600^{\circ} \mathrm{C}$, as shown in Figure 6 (d). The reason for the formation of thin-plate martensite due to aging at $600^{\circ} \mathrm{C}$ will be discussed later.

\section{3-4. Substructure of thin-plate martensite}

Figure 7 (a) shows the bright field image of the thin-plate martensite which formed in the specimen ausaged at $600^{\circ} \mathrm{C}$ for 4 hours. The martensite plate contains high density of transformation twins which traverse completely from the one plate edge to the other with no midrib. Such microstructural 

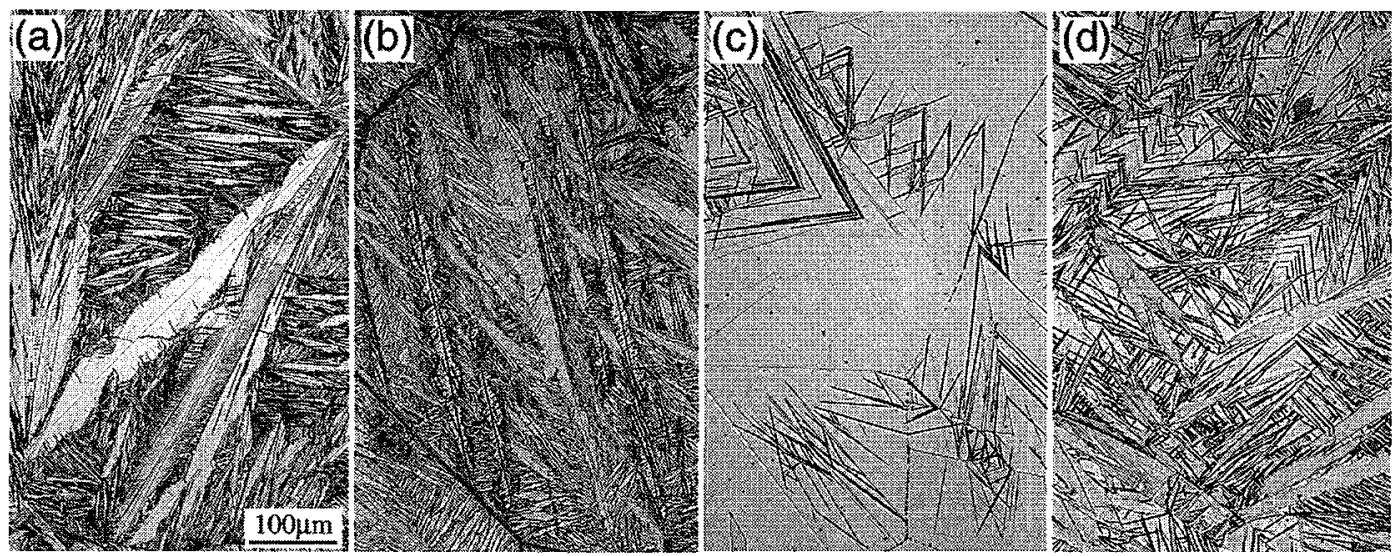

Figure 6 : Optical micrographs of martensite in the specimens as-quenched (a), aged at $700^{\circ} \mathrm{C}$ for 13.5 hours (b), and $400^{\circ} \mathrm{C}$ for 32 hours (c) and $600^{\circ} \mathrm{C}$ for 4 hours (d). All of them were cooled at $-196^{\circ} \mathrm{C}$.

characteristics are quite similar to those of thin-plate martensites in Fe-Ni-Co-Ti [12], Fe-Ni-C [2] and unaged $\mathrm{Fe}-28 \% \mathrm{Ni}-7.5 \% \mathrm{Si}$ alloys as previously reported [8]. Figure 7 (b) shows the selected area diffraction pattern (SADP) taken from this thin-plate martensite. It can be seen that there are some weak and streaked superlattice spots corresponding to $\{100\}_{\mathrm{L} 12}$ reflection between fundamental spots of BCC- $\alpha$ ' martensite as indicated by a white arrow. Since the streaks of the superlattice spots are along the $\langle 112\rangle_{M}$ direction which is comparable to that of the fundamental reflections, it can be concluded that the transformation twins of the matrix transit through the $\gamma^{\prime}$ particle. This result suggests that the $\gamma^{\prime}$ particles were elastically deformed by the martensitic transformation of the matrix in maintenance of the coherency with the matrix. In the ausaged $\mathrm{Fe}-\mathrm{Ni}-\mathrm{Ti}$ alloys, it has been reported that the critical size for inducing the elastic deformation of the $\gamma^{\prime}-(\mathrm{Ni}, \mathrm{Fe})_{3} \mathrm{Ti}$ particles by the martensitic transformation of the surrounding matrix is probably less than $4-5 \mathrm{~nm}$ [13]. In the present case, the critical size should be larger than about $10 \mathrm{~nm}$. The reason for the difference between these two cases is unclear at present and further studies are required.

The tetragonality of the $\alpha^{\prime}$ martensite was examined by XRD analysis, and it was confirmed that the c/a ratio of martensite changed from 1.00 (BCC) to 1.02 (BCT) due to ausaging at $600^{\circ} \mathrm{C}$ for 4 hours. This change can be explained as being due to the coherency precipitation of $\gamma^{\prime}$ with the $\mathrm{L}_{2}$ structure [10]. It is well known that large tetragonality of martensite facilitates the formation of thin-plate
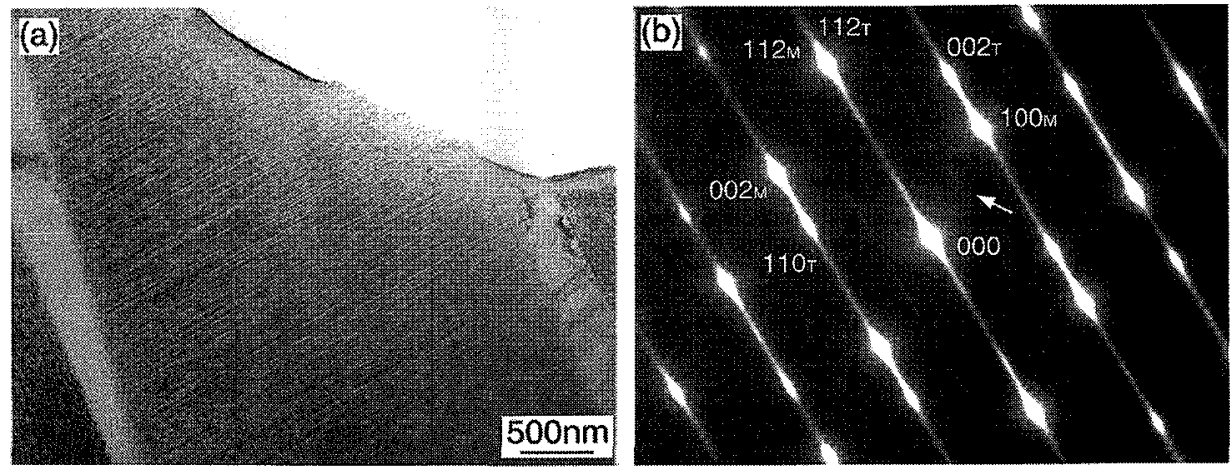

Figure 7 : (a) TEM micrograph and (b) SADP showing high density of twins in a martensite plate of the specimen aged at $600^{\circ} \mathrm{C}$ for 4 hours and cooled at $-196^{\circ} \mathrm{C}$. Incident beam direction is $[100]_{\mathrm{M}}$. 
martensite, as reviewed by Maki [14]. It can be speculated that formation of thin-plate martensite due to aging at $600^{\circ} \mathrm{C}$ was caused by the increase of tetragonality and by the precipitation hardening of austenite.

\section{SUMMARY}

(1) $\gamma^{\prime}-(\mathrm{Ni}, \mathrm{Fe})_{3} \mathrm{Si}$ particles with the $\mathrm{L} 1_{2}$ structure which are coherent with the austenite matrix were formed by ausaging at below $600^{\circ} \mathrm{C}$.

(2) The Ms temperature was greatly depressed by aging at below $500^{\circ} \mathrm{C}$, but the change by aging at $600^{\circ} \mathrm{C}$ was very small.

(3) Not only lenticular but thin-plate martensites were formed by aging at below $600^{\circ} \mathrm{C}$. The formation of thin-plate type martensite may have been brought about by the decrease of the Ms temperature, the hardening of austenite and the increase of the tetragonality of martensite due to ausaging.

\section{Acknowledgements}

The authors wish to thank Mr. S. Sasaki for help with the experimental work. One of the authors (R. Kainuma) acknowledges the support from the Steel Research Foundation by the Iron and Steel Institute of Japan (ISIJ).

\section{Reference}

[1] T. Maki : in Shape Memory Materials, edited by Otsuka and Wayman, (Cambridge University Press, 1998), p. 117.

[2] T. Maki, S. Shimooka, M. Umemoto and I. Tamura : Trans. JIM, 13 (1972) 400.

[3] S. Kajiwara : Trans. JIM, 26 (1985) 595.

[4] D. P. Dunne and C. M. Wayman : Metall. Trans., 4 (1973) 137.

[5] M. Umemoto and C. M. Wayman : Metall. Trans. A, 9A (1978) 891.

[6] T. Maki, K. Kobayashi, M. Minato and I. Tamura : Scr. Metall., 18 (1984) 1105.

[7] O. Ikeda, Y. Himuro, I. Ohnuma, R. Kainuma and K. Ishida : J. Alloys \& Comp., 268 (1998) 130.

[8] O. Ikeda, Y. Himuro, I. Ohnuma, R. Kainuma and K. Ishida : in The $3^{\text {rd }}$ Pacific Rim Int. Conf. On Advanced Materials and Processing (PRICOM), edited by M. A. Iman (TMS, 1998), p. 1503.

[9] Y. Himuro, O. Ikeda, I. Ohnuma, R. Kainuma and K. Ishida : Presented at the Annual Meeting of the Japan Institute of metals, (1999), Abstracts p. 358, Submitted to ISIJ International.

[10] J. K. Abraham and J. S. Pascover : Trans. AIME, 245 (1969) 759.

[11] E. Hornbogen and W. M. Mayer : Acta Metall., 15 (1967) 584

[12] T. Maki, S. Furutani and I. Tamura : ISIJ Int., 29 (1989) 438.

[13] T. Maki and C. M. Wayman : Acta Metall., 25 (1977) 695.

[14] T. Maki : in Proc. of MRS Int. Mtg. On Advanced Materials, vol. 9, edited by M. Doyama et al. (MRS, Pittsburgh, 1989), p. 415. 